\title{
Emerging Role of Immunity in Cerebral Small Vessel Disease
}

\author{
Ying Fu and Yaping Yan* \\ Key Laboratory of the Ministry of Education for Medicinal Resources and Natural Pharmaceutical Chemistry, National \\ Engineering Laboratory for Resource Development of Endangered Crude Drugs in Northwest of China, College of Life \\ Sciences, Shaanxi Normal University, Xi'an, China
}

Cerebral small vessel disease (CSVD) is one of the main causes of vascular dementia in older individuals. Apart from risk containment, efforts to prevent or treat CSVD are ineffective due to the unknown pathogenesis of the disease. CSVD, a subtype of stroke, is characterized by recurrent strokes and neurodegeneration. Blood-brain barrier (BBB) impairment, chronic inflammatory responses, and leukocyte infiltration are classical pathological features of CSVD. Understanding how BBB disruption instigates inflammatory and degenerative processes may be informative for CSVD therapy. Antigens derived from the brain are found in the peripheral blood of lacunar stroke patients, and antibodies and sensitized T cells against brain antigens are also detected in patients with leukoaraiosis. These findings suggest that antigen-specific immune responses could occur

OPEN ACCESS

Edited by:

Niccolo Terrando,

Duke University, United States

Reviewed by:

Adonis Sfera,

Loma Linda University, United States

Alyson Anne Miller, University of Glasgow, United Kingdom

*Correspondence: Yaping Yan yaping.yan@snnu.edu.cn

Specialty section: This article was submitted to Inflammation, a section of the journal Frontiers in Immunology

Received: 27 September 2017 Accepted: 10 January 2018 Published: 25 January 2018

Citation:

Fu Y and Yan Y (2018) Emerging Role of Immunity in Cerebral Small Vessel Disease. Front. Immunol. 9:67. doi: 10.3389/fimmu.2018.00067 in CSVD. This review describes the neurovascular unit features of CSVD, the immune responses to specific neuronal and glial processes that may be involved in a distinct mechanism of CSVD, and the current evidence of the association between mechanisms of inflammation and interventions in CSVD. We suggest that autoimmune activity should be assessed in future studies; this knowledge would benefit the development of effective therapeutic interventions in CSVD.

Keywords: cerebral small vessel disease, degeneration, pathogenesis, inflammation, autoimmune response

\section{INTRODUCTION}

Cerebral small vessel disease (CSVD) represents a diverse range of pathological changes that affect capillaries, small arteries and small veins in the brain. This disease is related to lacunar infarct, microbleeds, enlarged perivascular spaces, leukoaraiosis, and cortical atrophy. As such, CSVD causes $20 \%$ of strokes and constitutes a main source of cognitive decline, particularly in the elderly (1-4). However, apart from risk containment, efforts to prevent or to treat CSVD are ineffective $(5,6)$. The burdens of dementia and the cost to society imposed by CSVD are overwhelming and have incited efforts to explore new therapeutic resources $(7,8)$.

Immune responses have recently emerged as important elements contributing to the progression of stroke. Recent reviews in the literature have discussed the contribution of inflammatory mediators and lymphocytes to the development of brain lesions and neurological deficits that occur in acute ischemic stroke with large artery occlusion or acute cerebral hemorrhage (9-15). Recurrent minor stroke attacks in CSVD lead to blood-brain barrier (BBB) leakage (16-19), central nervous system (CNS) antigen release into the peripheral circulation and lymphocyte infiltration into brain tissue, which allow for the possibility of novel antigens deprived from the CNS to encounter the lymphocytes $(20,21)$. In addition to BBB disruption, blood proteins at the neurovascular unit 
activate microglia to produce chemokines, which cause peripheral inflammatory cells to migrate to the CNS, create a chronic inflammatory microenvironment and encourage activated lymphocytes to encounter CNS antigens (22-28). Immune responses in CSVD are not well characterized and may contribute to the pathogenesis of CSVD injury just as to those of multiple sclerosis (MS) and neuromyelitis optica (NMO), classic autoimmune disorders of the CNS. Therefore, we will focus on identifying specific characteristics of the role of the immune system in CSVD. We will compare imaging, pathology and immune features with MS. Such comparisons will be considered in relation to the use of disease-modifying drugs and their abilities to control the progression of CSVD. We believe that the identification of the differences and similarities in the immune mechanisms involved in CSVD and MS may potentially provide valuable hints to harness the use of disease-modifying drugs for the attenuation of inflammation and to improve clinical outcomes of patients with CSVD just as those in MS. The results from proof-of-concept clinical trials with fingolimod in both acute ischemic stroke and intracerebral hemorrhage (29-32), together with natalizumab in acute ischemic stroke (33), suggest that this concept is not only reasonable but also feasible (33).

\section{CSVD AND STROKE}

Stroke comprises the following pathological types: intracerebral hemorrhage, subarachnoid hemorrhage and ischemic stroke. Lacunar-type strokes account for $20-30 \%$ of ischemic strokes (34). Moreover, small hemorrhages and microbleeds can occur in lacunar stroke (35). Although lacunas and small hemorrhages may appear after clinical attacks, most of these types of stroke develop "silently." Experiencing numerous strokes is associated with diffuse white matter hyperintensities, cerebral atrophy, and enlarged perivascular space and thus doubles the risk of dementia $(1,36,37)$. This triggering of both small ischemic and hemorrhagic consequences by pathological small vessels and cerebral degeneration is collectively known as CSVD (4).

\section{BLOOD PROTEINS AT THE NEUROVASCULAR UNIT PROMOTE IMMUNE ACTION IN THE BRAIN}

Fibrin is a result of thrombin-mediated conversion of fibrinogen to an insoluble fibrin network, as the final product of the coagulation cascade. Human studies and experimental animal models provided evidence for the critical role of fibrin in inflammation $(38,39)$. Interactions between fibrin and microglia via TLR4 and CD11b/CD18 receptors were identified as direct activation pathways of the innate immune response $(23,40)$. Fibrin-induced activation of microglia triggers chemokine and cytokine secretion and stimulates leukocyte recruitment, thus leading to an inflammatory environment in the neurovascular unit (39). Importantly, Ryu et al. found that fibrin in the neurovascular unit of MS models was sufficient to induce the activation of myelin-specific T cells and infiltration into the CNS, demonstrating that a fibrin-induced innate immune response triggers
CNS autoimmunity $(23,40)$. Under normal conditions, blood proteins such as plasmin and fibrinogen are not detected in the parenchyma of the brain shielded by the intact $\mathrm{BBB}$. In response to $\mathrm{BBB}$ disruption and components from the blood entering the brain milieu, blood proteins-associated inflammation occurs in the CNS parenchyma.

Cerebral small vessel disease models, including chronic cerebral hypoperfusion and spontaneously hypertensive rats, have identified deficits in BBB integrity, which suggests a close spatial and temporal relationship between the extravasation of plasma constituents, brain tissue injury and subsequent inflammatory processes (41-45). BBB permeability has also been reported in CSVD patients. Albumin increases in the cerebrospinal fluid (CSF) of stroke patients $(46,47)$. Intrinsic small vessel disease results in vessel wall thickening, focal arteriolar dilatation, striking loss of normal vessel wall architecture, and extravasation of blood components into and through the wall; these findings were observed in post-mortem examinations (48-50). Neuroimaging provides considerable insights into the earliest stages of CSVD. Imaging studies revealed that $\mathrm{BBB}$ leakage is very subtle, persistent, and more spatially extensive in patients with $\operatorname{CSVD}(16,18,19)$; it even occurs prior to development of brain lesions (19).

Inflammatory cell infiltrations in the arteriolar wall and perivascular tissue have been noted in CSVD patients since 1902 (51-53). Moreover, clinical pathological data also demonstrated that the activation and proliferation of microglia induced the expression of MHC II and costimulatory molecules CD40 and B7-2, and the appearance of these cells in the parenchyma was accompanied by the disruption of the $\mathrm{BBB}$ and fibrinogen deposition, indicating that immune activation results from $\mathrm{BBB}$ disruption $(54,55)$. However, the mechanism of immune cell infiltration and activation is poorly understood in CSVD. More importantly, the contribution of immune cells to the development and progression of CSVD is also unclear.

A number of experimental studies were conducted to reveal the inflammatory pathogenesis mechanisms in $\operatorname{CSVD}(21,56)$. Rosenberg et al. found that BBB disruption and MMP-9-mediated migration of $\mathrm{T}$ lymphocytes was related to extensive white matter abnormalities and behavioral impairments in chronically hypertensive rats. Minocycline, which has anti-inflammatory actions, including MMP-9 inhibition, effectively restored white matter integrity in SHR-SP (45). Weise et al. also showed that SHR-SP developed brain atrophy, white matter loss, BBB leakage, microglial activation with IL- $1 \beta$ secretion, and lymphocyte migration, suggesting a role for $\mathrm{NK}$ and $\mathrm{T}$ cells in cerebrovascular inflammation and hypertension-related cognitive decline (21).

\section{IMMUNITY IN STROKE}

Acute insults to the brain in cerebral ischemic stroke or cerebral hemorrhage cause neuronal cell death and elicit local and diffuse inflammation. Damage-associated molecular patterns trigger resident cells and initiate cellular and humoral cascades $(57,58)$. Such inflammatory cascades induce the overexpression of adhesion molecules and increase BBB permeability, thus favoring cumulative inflammatory cell infiltration and contributing to an increase in local and global brain damage 
$(13,14,59)$. Furthermore, the continuous cytokine release starts a chronic inflammatory process that allows the dynamic shift of the macrophage and microglial canonical phenotype between M1 (classical activation) and M2 (alternative activation that is presumably the result of antigen-presenting cells migrating from the periphery) $(10,60)$.

The presence of autoimmune responses to brain antigens in stroke patients has been reported since the early 1970s (61-64). Shortly after stroke onset, brain-derived antigens (e.g., MBP, GFAP, CK-BB, NSE, and S100) were present within the peripheral circulation $(65,66)$ and cervical lymph nodes $(67,68)$. In addition, lymphocytes traffic into the infarcted brain tissue within days after stroke (69-72), allowing for the possibility of a novel antigen to encounter the CNS (7). Concerning the systemic immune system, these antigens are essentially novel, indicating that lymphocytes encountering such an antigen could lead to the development of an autoimmune response (6).

In recent years, Becker et al. conducted a series of studies about autoimmunity in stroke, mainly the cellular immune response. Similar to other clinical studies, they found that cellular immune responses (Th1 type) to brain antigens occurred in patients with acute stroke (73-76). Furthermore, they found that the Th1 response to $\mathrm{MBP}$ was an independent predictor of stroke outcome, and more robust cellular responses to MBP were associated with a decreased likelihood of a good outcome (76). The same results were also found in stroke models $(77,78)$. At the time of stroke, animal models subjected to infections or systemic inflammatory stimuli are predisposed to develop an autoimmune response to the brain, and this response is related to poor outcomes (79-81). Accordingly, the induction of MBP-induced or MOG-induced tolerance was found to prevent CNS autoimmunity and improve outcomes in experimental stroke (82-86). Offner et al. also found that MOG-reactive cells invaded the CNS and exacerbated stoke severity, further substantiating the idea that the cellular immune response might affect stroke outcomes (87). In contrast, Meisel et al. showed that stroke-induced immunodepression might represent an adaptive mechanism that inhibited long-lasting antigen-derived brain cellular immune responses $(88,89)$.

The presence of antibodies to brain antigens has been described in stroke. Immunoglobulins are present in the CSF of approximately $25 \%$ of survivors in the chronic phase of stroke (90-92). Some autoantibodies to brain antigens (e.g., MBP, PLP, $\mathrm{NF}$, and NR2A/2B) have been documented in individuals after stroke (93-97). In a study with 40 patients, anti-MBP antibody titers were associated with cognitive decline during the first year after stroke (98), but we still do not completely understand the pathological consequences of this humoral response. In a stroke model study, researchers found that mice with B lymphocyte infiltrates in their infarct cores developed late cognitive decline and that blocking the $\mathrm{B}$ cell response using a mouse analog of rituximab, an FDA-approved anti-CD20 antibody, prevented this cognitive decline. This result provides evidence that autoantibodies can interfere with neuronal function and could mediate cognitive impairment after stroke (99).

The type of immune response that develops to a particular antigen is dependent upon the microenvironment at the site of antigen encounter (100). Th1-type response, which is associated with the cellular immune response, is favored by an inflammatory microenvironment where IFN- $\gamma$ is present, such as what might occur during a systemic infection; Th2-type response, which is classically associated with humoral immunity and antibody secretion, is favored by the presence of cytokines such as IL-4 (101-105). However, the cellular immune response or humoral immune response depends on the local microenvironment and the presence of costimulatory molecules. CSVD is a cerebral vascular disorder characterized by recurrent strokes with sustainable BBB disruption as well as a chronic inflammatory response at the neurovascular unit. Therefore, it is possible that immune tolerance could be damaged in stroke under certain chronic inflammatory circumstances in CSVD. As mentioned previously, blood proteins at the neurovascular unit play an important role in the communication between the brain and the immune system (Figure 1). However, it is still unknown whether fibrin triggers and sustains antigen-specific lymphocytes in the CNS of patients with acute brain injury in chronic phase.

\section{UNDERSTANDING THE UNIQUE IMMUNE MECHANISMS IN CSVD IS INSTRUMENTAL FOR IMMUNE INTERVENTIONAL THERAPIES}

Stroke does not systematically trigger autoimmunity; however, under certain circumstances such as pronounced microenvironment inflammation, autoreactive $\mathrm{T}$ cells could escape the tolerance controls and induce antigen-specific immune responses (Figure 1). CSVD is characterized by recurrent strokes with cumulative disabilities and vascular dementia (Table 1). At the onset of ischemic and hemorrhagic stroke (attack phase), emerging evidence has revealed that stroke induced a local inflammatory reaction and a plethora of innate immune responses in the brain where antigen-presenting cells became prominent; following the onset of stroke, inflammatory components (IL-4 or IFN- $\gamma$ ), which are produced by innate immune cells (e.g., microglia, NK cell) with the stimulation of blood proteins at the neurovascular unite, promote detrimental cellular or humoral responses and lead to diffuse neuron and oligodendrocyte damage (101-105). In chronic stages (remitting phase), the chronic inflammatory activity that is triggered by blood proteins at neurovascular units might also participate in post-stroke cognitive decline and neurodegeneration $(39,40)$.

The slow developments of CSVD suggest that exploring the mechanisms and interventions for its prevention or treatment will need long-term study for recurrent acute minor stroke and chronic progress neurodegeneration. A disease-modifying strategy aimed at changing the natural course of an illness is primarily applied to treat chronic diseases. In the field of neurological disorders, this concept has been used for neuroinflammatory diseases such as MS. Given the similarities in the inflammatory mechanisms and clinical characters of MS and CSVD (Table 1), one would ideally expect that CSVD requires a similar immunotherapeutic and preventive approach to that used for MS.

Fingolimod became the first oral drug to be FDA-approved for the treatment of relapsing-remitting MS. This drug can act 


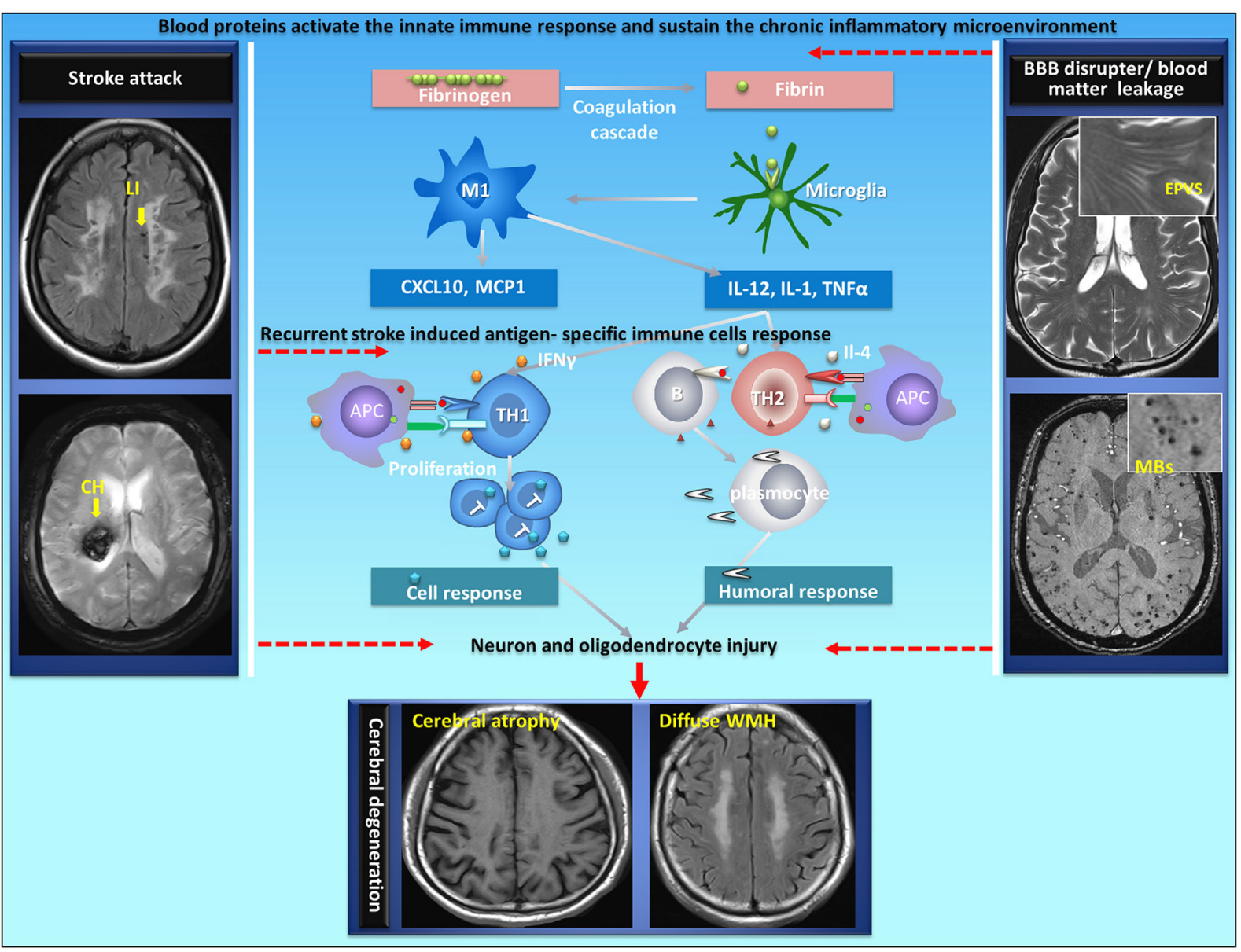

FIGURE 1 | Proposed autoimmunity mechanism in the development of neurodegeneration in CSVD. CSVD is a cerebral vascular disorder characterized by recurrent strokes with sustainable BBB disruption as well as a chronic inflammatory response at the neurovascular unit. Autoimmunity could be generated in acute stroke under certain brain chronic inflammatory circumstances with damaged immune tolerance in CSVD. Blood proteins at the neurovascular unit play an important role in the communication between the brain and the immune system. During BBB disruption, fibrinogen extravagates into the CNS and is converted to fibrin upon activation of coagulation. Fibrin, the high-affinity plasma-derived ligand for CD11b/CD18, activates CNS-resident innate immune cells (microglia and perivascular macrophages) to stimulate cytokine release, thus sustaining antigen-presenting properties by providing instructive signals (such asIL-12, IL-1, and TNF $\alpha$ ) to promote antigen-specific (neuron or oligodendrocyte) Th1-cell or Th2-cell differentiation following a stroke. The cellular immune response or humoral immune response leads to neuron and oligodendrocyte injury. APC, antigen-presenting cells; LI, lacunar infarct; $\mathrm{CH}$, cerebral hemorrhage; EPVS, enlarged perivascular space; MBs, microbleeds; CSVD, cerebral small vessel disease; BBB, blood-brain barrier. The original data were acquired in the YPY group.

on four of the five known S1P receptor subtypes (S1PR1, S1PR3, S1PR4, S1PR5) and exerts its immunomodulatory actions by affecting lymphocyte numbers, trafficking and apoptosis through $\mathrm{S} 1 \mathrm{P}$ receptors. Specifically, fingolimod reduces circulating lymphocytes by preventing their egress from lymph nodes during stroke, and fingolimod might contribute to the prevention of the early infiltration of lymphocytes into the brain, thus reducing thromboinflammation (106-108). In our three open-label trials, patients with acute ischemic or hemorrhagic stroke were treated with oral fingolimod for 3 days after the onset of symptoms, and consequently, microvascular permeability and secondary injury were reduced in these patients (29-32). However, the action of fingolimod in acute stages involved in diffuse brain injury and cerebral degeneration is still poorly understood and needs to be elucidated $(109,110)$. A recent study found that fingolimod could induce VEGF expression of astrocytes by stimulating
S1PR3, which plays a role in the breakdown of the BBB, a step critical to the entry of pathogenic lymphocytes into the brain (111). Of note, BBB leakage induced by fingolimod due to the activation of S1PR3 in astrocytes may limit its use, and selective S1PR1 agonist (e.g., LASW1238, RP101075) treatment should be further optimized $(112,113)$.

Natalizumab blocks $\alpha 4$-integrin, which mediates the invasion of lymphocytes (mainly T cells) into the CNS, and currently represents one of the most effective therapies for relapsing-remitting MS. The ACTION study, a randomized controlled phase IIa trial comparing the effect of a single injection of $300 \mathrm{mg}$ of intravenous natalizumab and placebo within a 9-h time window after symptom onset, found no effect of natalizumab on infarct growth, but patients receiving natalizumab were more likely to have an excellent cognition outcome at 90 days. This outcome was particularly evident in subgroups of patients with smaller 
TABLE 1 | Contrasting features of clinical, imaging, pathology and inflammation between CSVD and MS.

\begin{tabular}{|c|c|c|}
\hline & CSVD & MS \\
\hline \multicolumn{3}{|l|}{ Clinical features } \\
\hline Course of disease & A chronic disease & A chronic disease \\
\hline Attack events & Lacunar infarct and cerebral hemorrhage & Inflammatory demyelination activation \\
\hline Disability & Accumulation & Accumulation \\
\hline Neurodegeneration & Cognition, gait, neuropsychology and sleep disturbance & Cognition, gait, neuropsychology and sleep disturbance \\
\hline \multicolumn{3}{|l|}{ Brain MRI } \\
\hline T2/FLAIR white matter hyperintensities & Focal and diffuse & Focal and diffuse \\
\hline T1 hypointensities & Transient and persistent & Transient and persistent \\
\hline Microbleeds & Common & Rare \\
\hline Contrast enhancing lesions & Common at stroke recurrent stage, rare at remitting stage & Common at relapse phase, rare at remitting stage \\
\hline Enlarged perivascular space & Centrum semiovale and basal ganglion region & Centrum semiovale region \\
\hline Cerebral atrophy & Gray matter reduced and ventricles gradually expanded & Gray matter reduced and ventricles gradually expanded \\
\hline \multicolumn{3}{|l|}{ Pathology features } \\
\hline Demyelinating region & Arterial watershed areas & High venule density and arterial watershed areas \\
\hline Myelin & Selective loss of phospholipids and MAG with PLP preservation & Myelin loss with selective reduction of phospholipids \\
\hline Axonal & Loss & Loss \\
\hline Blood-brain barrier & Increased permeability and fibrin leakage & Increased permeability and fibrin leakage \\
\hline Perivascular & Perivascular collagenases and inflammatory & Perivascular collagenases and inflammatory cuffs \\
\hline Inflammatory cell & Microglia and astrocyte activation and lymphocytic infiltration & $\begin{array}{l}\text { Microglia and astrocyte activation and lymphocytic } \\
\text { infiltration }\end{array}$ \\
\hline \multicolumn{3}{|l|}{ Inflammation features } \\
\hline Triggering events for immune activation & Cell death products, microglia activation & Mostly unidentified \\
\hline Location of activation signals & Brain and periphery & Periphery \\
\hline Antigen specificity & Mostly antigen-specific cells and antigen-specific antibody & Mostly antigen-specific cells \\
\hline Immune effector cells & Combined effects of many cells, no dominant cell type & Coordinated events dominated by $T$ cells \\
\hline Role of inflammatory mediators & Presumably many, including IFN- $\gamma, \mathrm{IL}-17, \mathrm{IL}-4$ & Presumably many, including TNF-a, IFN- $\gamma, \mathrm{IL}-17$ \\
\hline Efficacy of immune modulation & Under investigation & $\begin{array}{l}13 \text { FDA-approved, disease-modifying drugs, moderate } \\
\text { to high efficacy }\end{array}$ \\
\hline
\end{tabular}

infarcts. This result suggests that mitigating diffuse neuroinflammation triggered by acute stroke may additionally mitigate cerebral degeneration, especially in minor stroke. Considering the safety and efficacy of fingolimod and natalizumab in acute stroke, future preclinical animal experiments and translational clinical trials involving fingolimod and natalizumab treatment for CSVD are expected.

Dimethyl fumarate (DMF) is utilized as an oral drug to treat MS and has been demonstrated to be as potent as several other drugs but with fewer side effects $(114,115)$. The beneficial effects of this medication were consistent with regulation of $\mathrm{CD}^{+}$ Th1 cell differentiation. More importantly, DMF was discovered to impact the anti-oxidative stress cell machinery to promote the transcription of genes downstream of the activation of the nuclear factor Nrf2 $(116,117)$. It was reported that DMF might be useful for treating acute stroke. In acute stroke models, DMF prevented cerebral edema progression at the acute stage and promoted recovery at the chronic stage (118-120). Recently, an experiment using mice with bilateral common carotid artery stenosis revealed that DMF decreased microglia/macrophage activation, protected against white matter injury and improved cognition impairment (121). Multiple immunomodulatory and anti-oxidative stress actions support DMF as an appealing medication; however, its potential for impacting the degenerative aspects of CSVD remains to be explored.

Rituximab is FDA approved as a B-cell-depleting drug for rheumatoid arthritis, non-Hodgkin's lymphoma, chronic lymphocytic leukemia, and microscopic polyangiitis. Rituximab was also found to be effective in decreasing the autoantigenspecific humoral immune response or inhibiting inflammatory responses orchestrated by pathogenic B cells in patients with MS and NMO (122-127). Although both deleterious and protective regulatory roles of $\mathrm{B}$ lymphocytes have been increasingly recognized, translation of these roles of B lymphocytes into clinical trials in stroke has not yet occurred. However, pharmacological ablation of B lymphocytes using rituximab after 5 days of stroke prevents the appearance of delayed cognitive deficits in an animal stroke model with large vessel occlusion (99). Nevertheless, this finding suggests that rituximab treatment could be a promising therapy for CSVD, given the production of brain-reactive antibodies associated with cognitive decline in stroke patients (98).

Minocycline is a tetracycline antibiotic agent that has multiple immune-modulating properties; clinical data have shown the activity of minocycline in patients with MS or clinically isolated syndrome with a good safety profile (128-132). Minocycline also reduces infarct size in acute stroke clinical trials $(132,133)$. More recently, Rosenberg et al. found that minocycline decreased hypoxia-induced infiltration of leukocytes, reduced white matter damage, improved behavior, and prolonged life in CSVD models $(44,45)$. Since minocycline is used as an antibiotic in the clinical setting, its safety for human use has been extensively evaluated. Moreover, the multiple neuroprotective effects of minocycline in vascular injury models support its use as a potential therapeutic treatment for CSVD (134-138). 


\section{CONCLUSION AND FUTURE DIRECTIONS}

Brain proteins are detected in the blood of stroke/lacunar stroke patients $(64,66)$. Antibodies against brain antigens develop in patients with leukoaraiosis (94), suggesting a humoral immune response to the brain injury in CSVD. Furthermore, the presence of circulating $\mathrm{T}$ cells sensitized against brain antigens and antigen-presenting cells carrying brain antigens in the draining lymphoid tissue of stroke patients indicate that stroke might induce antigen-specific immune responses similar to those found in MS patients. We do not know whether poststroke dementia via lymphocyte-mediated autoimmunity has detrimental effects; however, clinical and preclinical trials of immune modulation using lymphocyte-targeted approaches have yielded some promising results in cognitive degeneration after stroke $(33,99)$. Impaired tissue oxygenation, induced inflammatory responses, and induced leukocyte infiltration are classical pathological features in CSVD (Table 1). In theory, mitigating chronic and diffuse

\section{REFERENCES}

1. Pantoni L. Cerebral small vessel disease: from pathogenesis and clinical characteristics to therapeutic challenges. Lancet Neurol (2010) 9:689-701. doi:10.1016/S1474-4422(10)70104-6

2. A united approach to vascular disease and neurodegeneration. Lancet Neurol (2012) 11:293. doi:10.1016/S1474-4422(12)70050-9

3. Wardlaw JM, Smith C, Dichgans M. Mechanisms of sporadic cerebral small vessel disease: insights from neuroimaging. Lancet Neurol (2013) 12:483-97. doi:10.1016/S1474-4422(13)70060-7

4. Wardlaw JM, Smith EE, Biessels GJ, Cordonnier C, Fazekas F, Frayne R, et al. Neuroimaging standards for research into small vessel disease and its contribution to ageing and neurodegeneration. Lancet Neurol (2013) 12:822-38. doi:10.1016/S1474-4422(13)70124-8

5. Investigators SPS, Benavente OR, Hart RG, McClure LA, Szychowski JM, Coffey CS, et al. Effects of clopidogrel added to aspirin in patients with recent lacunar stroke. NEngl J Med (2012) 367:817-25. doi:10.1056/NEJMoa1204133

6. Pearce LA, McClure LA, Anderson DC, Jacova C, Sharma M, Hart RG, et al. Effects of long-term blood pressure lowering and dual antiplatelet treatment on cognitive function in patients with recent lacunar stroke: a secondary analysis from the SPS3 randomised trial. Lancet Neurol (2014) 13:1177-85. doi:10.1016/S1474-4422(14)70224-8

7. Arboix A, Blanco-Rojas L, Marti-Vilalta JL. Advancements in understanding the mechanisms of symptomatic lacunar ischemic stroke: translation of knowledge to prevention strategies. Expert Rev Neurother (2014) 14:261-76. doi:10.1586/14737175.2014.884926

8. Bath PM, Wardlaw JM. Pharmacological treatment and prevention of cerebral small vessel disease: a review of potential interventions. Int J Stroke (2015) 10:469-78. doi:10.1111/ijs.12466

9. Macrez R, Ali C, Toutirais O, Le Mauff B, Defer G, Dirnagl U, et al. Stroke and the immune system: from pathophysiology to new therapeutic strategies. Lancet Neurol (2011) 10:471-80. doi:10.1016/S1474-4422(11)70066-7

10. Chamorro A, Meisel A, Planas AM, Urra X, van de Beek D, Veltkamp R. The immunology of acute stroke. Nat Rev Neurol (2012) 8:401-10. doi:10.1038/ nrneurol.2012.98

11. Fu Y, Liu Q, Anrather J, Shi FD. Immune interventions in stroke. Nat Rev Neurol (2015) 11:524-35. doi:10.1038/nrneurol.2015.144

12. Wang J. Preclinical and clinical research on inflammation after intracerebral hemorrhage. Prog Neurobiol (2010) 92:463-77. doi:10.1016/j. pneurobio.2010.08.001

13. Mracsko E, Veltkamp R. Neuroinflammation after intracerebral hemorrhage. Front Cell Neurosci (2014) 8:388. doi:10.3389/fncel.2014.00388

14. Iadecola C, Anrather J. The immunology of stroke: from mechanisms to translation. Nat Med (2011) 17:796-808. doi:10.1038/nm.2399 neuroinflammation triggered by recurrent brain injury attack to prevent cerebral degeneration could be a feasible strategy against CSVD. However, one challenge to the advancement of the field is the incomplete understanding of the complex interactions between the immune system and the brain in CSVD. Therefore, the involvement of autoimmunity in CSVD should be cautiously assessed in future studies to facilitate the development of effective therapeutic interventions for CSVD.

\section{AUTHOR CONTRIBUTIONS}

YF and YY wrote and approved the final version of this manuscript.

\section{FUNDING}

YP was supported by the National Natural Science Foundation of China (81371372, 81571596, and 81771279) and the Fundamental Research Funds for the Central Universities (GK201701009).

15. Eltzschig HK, Carmeliet P. Hypoxia and inflammation. N Engl J Med (2011) 364:656-65. doi:10.1056/NEJMra0910283

16. Wardlaw JM, Doubal F, Armitage P, Chappell F, Carpenter T, Munoz Maniega S, et al. Lacunar stroke is associated with diffuse blood-brain barrier dysfunction. Ann Neurol (2009) 65:194-202. doi:10.1002/ana.21549

17. Wardlaw JM, Doubal FN, Valdes-Hernandez M, Wang X, Chappell FM, Shuler K, et al. Blood-brain barrier permeability and long-term clinical and imaging outcomes in cerebral small vessel disease. Stroke (2013) 44:525-7. doi:10.1161/ STROKEAHA.112.669994

18. Huisa BN, Caprihan A, Thompson J, Prestopnik J, Qualls CR, Rosenberg GA. Long-term blood-brain barrier permeability changes in Binswanger disease. Stroke (2015) 46:2413-8. doi:10.1161/STROKEAHA.115.009589

19. Zhang CE, Wong SM, van de Haar HJ, Staals J, Jansen JF, Jeukens CR, et al. Bloodbrain barrier leakage is more widespread in patients with cerebral small vessel disease. Neurology (2017) 88:426-32. doi:10.1212/WNL.0000000000003556

20. Engelhardt B, Carare RO, Bechmann I, Flugel A, Laman JD, Weller RO. Vascular, glial, and lymphatic immune gateways of the central nervous system. Acta Neuropathol (2016) 132:317-38. doi:10.1007/s00401-016-1606-5

21. Kaiser D, Weise G, Moller K, Scheibe J, Posel C, Baasch S, et al. Spontaneous white matter damage, cognitive decline and neuroinflammation in middleaged hypertensive rats: an animal model of early-stage cerebral small vessel disease. Acta Neuropathol Commun (2014) 2:169. doi:10.1186/s40478014-0169-8

22. Schachtrup C, Lu P, Jones LL, Lee JK, Lu J, Sachs BD, et al. Fibrinogen inhibits neurite outgrowth via beta 3 integrin-mediated phosphorylation of the EGF receptor. Proc Natl Acad Sci U S A (2007) 104:11814-9. doi:10.1073/ pnas.0704045104

23. Ryu JK, Petersen MA, Murray SG, Baeten KM, Meyer-Franke A, Chan JP, et al. Blood coagulation protein fibrinogen promotes autoimmunity and demyelination via chemokine release and antigen presentation. Nat Commun (2015) 6:8164. doi:10.1038/ncomms9164

24. Bardehle S, Rafalski VA, Akassoglou K. Breaking boundaries-coagulation and fibrinolysis at the neurovascular interface. Front Cell Neurosci (2015) 9:354. doi:10.3389/fncel.2015.00354

25. Akassoglou K. Coagulation takes center stage in inflammation. Blood (2015) 125:419-20. doi:10.1182/blood-2014-11-609222

26. Cai W, Zhang K, Li P, Zhu L, Xu J, Yang B, et al. Dysfunction of the neurovascular unit in ischemic stroke and neurodegenerative diseases: an aging effect. Ageing Res Rev (2017) 34:77-87. doi:10.1016/j.arr.2016.09.006

27. Hu X, De Silva TM, Chen J, Faraci FM. Cerebral vascular disease and neurovascular injury in ischemic stroke. Circ Res (2017) 120:449-71. doi:10.1161/ CIRCRESAHA.116.308427

28. Sixt M, Engelhardt B, Pausch F, Hallmann R, Wendler O, Sorokin LM. Endothelial cell laminin isoforms, laminins 8 and 10, play decisive roles 
in $\mathrm{T}$ cell recruitment across the blood-brain barrier in experimental autoimmune encephalomyelitis. J Cell Biol (2001) 153:933-46. doi:10.1083/ jcb.153.5.933

29. Zhu Z, Fu Y, Tian D, Sun N, Han W, Chang G, et al. Combination of the immune modulator fingolimod with alteplase in acute ischemic stroke: a pilot trial. Circulation (2015) 132:1104-12. doi:10.1161/CIRCULATIONAHA. 115.016371

30. Fu Y, Zhang N, Ren L, Yan Y, Sun N, Li YJ, et al. Impact of an immune modulator fingolimod on acute ischemic stroke. Proc Natl Acad Sci U S A (2014) 111:18315-20. doi:10.1073/pnas.1416166111

31. Li YJ, Chang GQ, Liu Y, Gong Y, Yang C, Wood K, et al. Fingolimod alters inflammatory mediators and vascular permeability in intracerebral hemorrhage. Neurosci Bull (2015) 31:755-62. doi:10.1007/s12264-015-1532-2

32. Fu Y, Hao J, Zhang N, Ren L, Sun N, Li YJ, et al. Fingolimod for the treatment of intracerebral hemorrhage: a 2-arm proof-of-concept study. JAMA Neurol (2014) 71:1092-101. doi:10.1001/jamaneurol.2014.1065

33. Elkins J, Veltkamp R, Montaner J, Johnston SC, Singhal AB, Becker K, et al. Safety and efficacy of natalizumab in patients with acute ischaemic stroke (ACTION): a randomised, placebo-controlled, double-blind phase 2 trial. Lancet Neurol (2017) 16:217-26. doi:10.1016/S1474-4422(16)30357-X

34. Warlow C, Sudlow C, Dennis M, Wardlaw J, Sandercock P. Stroke. Lancet (2003) 362:1211-24. doi:10.1016/S0140-6736(03)14544-8

35. Arboix A, Garcia-Eroles L, Massons J, Oliveres M, Targa C. Hemorrhagic lacunar stroke. Cerebrovasc Dis (2000) 10:229-34. doi:10.1159/000016061

36. Vermeer SE, Longstreth WT Jr, Koudstaal PJ. Silent brain infarcts: a systematic review. Lancet Neurol (2007) 6:611-9. doi:10.1016/S1474-4422(07)70170-9

37. van Veluw SJ, Shih AY, Smith EE, Chen C, Schneider JA, Wardlaw JM, et al. Detection, risk factors, and functional consequences of cerebral microinfarcts. Lancet Neurol (2017) 16:730-40. doi:10.1016/S1474-4422(17)30196-5

38. Hoppe B, Dorner T. Coagulation and the fibrin network in rheumatic disease: a role beyond haemostasis. Nat Rev Rheumatol (2012) 8:738-46. doi:10.1038/ nrrheum.2012.184

39. Davalos D, Akassoglou K. Fibrinogen as a key regulator of inflammation in disease. Semin Immunopathol (2012) 34:43-62. doi:10.1007/s00281-011-0290-8

40. Smiley ST, King JA, Hancock WW. Fibrinogen stimulates macrophage chemokine secretion through toll-like receptor 4. J Immunol (2001) 167:2887-94. doi:10.4049/jimmunol.167.5.2887

41. Holland PR, Searcy JL, Salvadores N, Scullion G, Chen G, Lawson G, et al. Gliovascular disruption and cognitive deficits in a mouse model with features of small vessel disease. J Cereb Blood Flow Metab (2015) 35:1005-14. doi:10.1038/jcbfm.2015.12

42. Choi JY, Cui Y, Kim BG. Interaction between hypertension and cerebral hypoperfusion in the development of cognitive dysfunction and white matter pathology in rats. Neuroscience (2015) 303:115-25. doi:10.1016/j.neuroscience. 2015.06.056

43. Candelario-Jalil E, Thompson J, Taheri S, Grossetete M, Adair JC, Edmonds E, et al. Matrix metalloproteinases are associated with increased blood-brain barrier opening in vascular cognitive impairment. Stroke (2011) 42:1345-50. doi:10.1161/STROKEAHA.110.600825

44. Jalal FY, Yang Y, Thompson J, Lopez AC, Rosenberg GA. Myelin loss associated with neuroinflammation in hypertensive rats. Stroke (2012) 43:1115-22. doi:10.1161/STROKEAHA.111.643080

45. Jalal FY, Yang Y, Thompson JF, Roitbak T, Rosenberg GA. Hypoxia-induced neuroinflammatory white-matter injury reduced by minocycline in SHR/SP. J Cereb Blood Flow Metab (2015) 35:1145-53. doi:10.1038/jcbfm.2015.21

46. Skoog I, Wallin A, Fredman P, Hesse C, Aevarsson O, Karlsson I, et al. A population study on blood-brain barrier function in 85-year-olds: relation to Alzheimer's disease and vascular dementia. Neurology (1998) 50:966-71. doi:10.1212/WNL.50.4.966

47. Taheri S, Gasparovic C, Huisa BN, Adair JC, Edmonds E, Prestopnik J, et al. Blood-brain barrier permeability abnormalities in vascular cognitive impairment. Stroke (2011) 42:2158-63. doi:10.1161/STROKEAHA.110.611731

48. Fisher CM. Lacunar strokes and infarcts: a review. Neurology (1982) 32:871-6. doi:10.1212/WNL.32.8.871

49. Fisher CM. The arterial lesions underlying lacunes. Acta Neuropathol (1968) 12:1-15. doi:10.1007/BF00685305

50. Fisher CM. Capsular infarcts: the underlying vascular lesions. Arch Neurol (1979) 36:65-73. doi:10.1001/archneur.1979.00500380035003
51. Lu J, Moochhala S, Kaur C, Ling EA. Cellular inflammatory response associated with breakdown of the blood-brain barrier after closed head injury in rats. J Neurotrauma (2001) 18:399-408. doi:10.1089/089771501750170976

52. Ogata J. The arterial lesions underlying cerebral infarction. Neuropathology (1999) 19:112-8. doi:10.1046/j.1440-1789.1999.00216.x

53. Bailey EL, Smith C, Sudlow CL, Wardlaw JM. Pathology of lacunar ischemic stroke in humans - a systematic review. Brain Pathol (2012) 22:583-91. doi:10.1111/j.1750-3639.2012.00575.x

54. Simpson JE, Ince PG, Higham CE, Gelsthorpe CH, Fernando MS, Matthews F, et al. Microglial activation in white matter lesions and nonlesional white matter of ageing brains. Neuropathol Appl Neurobiol (2007) 33:670-83. doi:10.1111/j.1365-2990.2007.00890.x

55. Tomimoto H, Akiguchi I, Wakita H, Lin JX, Budka H. Cyclooxygenase-2 is induced in microglia during chronic cerebral ischemia in humans. Acta Neuropathol (2000) 99:26-30. doi:10.1007/PL00007402

56. Bailey EL, Smith C, Sudlow CL, Wardlaw JM. Is the spontaneously hypertensive stroke prone rat a pertinent model of sub cortical ischemic stroke? A systematic review. Int J Stroke (2011) 6:434-44. doi:10.1111/j.1747-4949.2011.00659.x

57. Liesz A, Dalpke A, Mracsko E, Antoine DJ, Roth S, Zhou W, et al. DAMP signaling is a key pathway inducing immune modulation after brain injury. J Neurosci (2015) 35:583-98. doi:10.1523/JNEUROSCI.2439-14.2015

58. Kono H, Rock KL. How dying cells alert the immune system to danger. Nat Rev Immunol (2008) 8:279-89. doi:10.1038/nri2215

59. Chen S, Yang Q, Chen G, Zhang JH. An update on inflammation in the acute phase of intracerebral hemorrhage. Transl Stroke Res (2015) 6:4-8. doi:10.1007/s12975-014-0384-4

60. Gliem M, Mausberg AK, Lee JI, Simiantonakis I, van Rooijen N, Hartung HP, et al. Macrophages prevent hemorrhagic infarct transformation in murine stroke models. Ann Neurol (2012) 71:743-52. doi:10.1002/ana.23529

61. Miro-Mur F, Urra X, Gallizioli M, Chamorro A, Planas AM. Antigen presentation after stroke. Neurotherapeutics (2016) 13:719-28. doi:10.1007/ s13311-016-0469-8

62. Urra X, Miro F, Chamorro A, Planas AM. Antigen-specific immune reactions to ischemic stroke. Front Cell Neurosci (2014) 8:278. doi:10.3389/ fncel.2014.00278

63. Santos Samary C, Pelosi P, Leme Silva P, Rieken Macedo Rocco P. Immunomodulation after ischemic stroke: potential mechanisms and implications for therapy. Crit Care (2016) 20:391. doi:10.1186/s13054-016-1573-1

64. Chiva-Blanch G, Suades R, Crespo J, Peña E, Padró T, Jiménez-Xarrié E, et al. Microparticle shedding from neural progenitor cells and vascular compartment cells is increased in ischemic stroke. PLoS One (2016) 11:e0148176. doi:10.1371/journal.pone.0148176

65. Jauch EC, Lindsell C, Broderick J, Fagan SC, Tilley BC, Levine SR, et al. Association of serial biochemical markers with acute ischemic stroke: the National Institute of Neurological Disorders and Stroke recombinant tissue plasminogen activator Stroke Study. Stroke (2006) 37:2508-13. doi:10.1161/01. STR.0000242290.01174.9e

66. Herrmann M, Vos P, Wunderlich MT, de Bruijn CH, Lamers KJ. Release of glial tissue-specific proteins after acute stroke: a comparative analysis of serum concentrations of protein S-100B and glial fibrillary acidic protein. Stroke (2000) 31:2670-7. doi:10.1161/01.STR.31.11.2670

67. van Zwam M, Huizinga R, Melief MJ, Wierenga-Wolf AF, van Meurs M, Voerman JS, et al. Brain antigens in functionally distinct antigen-presenting cell populations in cervical lymph nodes in MS and EAE. J Mol Med (2009) 87:273-86. doi:10.1007/s00109-008-0421-4

68. Planas AM, Gomez-Choco M, Urra X, Gorina R, Caballero M, Chamorro A. Brain-derived antigens in lymphoid tissue of patients with acute stroke. J Immunol (2012) 188:2156-63. doi:10.4049/jimmunol.1102289

69. Gelderblom M, Leypoldt F, Steinbach K, Behrens D, Choe CU, Siler DA, et al. Temporal and spatial dynamics of cerebral immune cell accumulation in stroke. Stroke (2009) 40:1849-57. doi:10.1161/STROKEAHA.108.534503

70. Schwab JM, Nguyen TD, Meyermann R, Schluesener HJ. Human focal cerebral infarctions induce differential lesional interleukin-16 (IL-16) expression confined to infiltrating granulocytes, CD8+ T-lymphocytes and activated microglia/macrophages. J Neuroimmunol (2001) 114:232-41. doi:10.1016/ S0165-5728(00)00433-1

71. Zhou W, Liesz A, Bauer H, Sommer C, Lahrmann B, Valous N, et al. Postischemic brain infiltration of leukocyte subpopulations differs among 
murine permanent and transient focal cerebral ischemia models. Brain Pathol (2013) 23:34-44. doi:10.1111/j.1750-3639.2012.00614.x

72. Mracsko E, Javidi E, Na SY, Kahn A, Liesz A, Veltkamp R. Leukocyte invasion of the brain after experimental intracerebral hemorrhage in mice. Stroke (2014) 45:2107-14. doi:10.1161/STROKEAHA.114.005801

73. Kallen B, Nilsson O, Thelin C. Effect of encephalitogenic protein on migration in agarose of leukoytes from patients with multiple sclerosis. A longitudinal study of patients with relapsing multiple sclerosis or with cerebral infarction. Acta Neurol Scand (1977) 55:47-56. doi:10.1111/j.1600-0404.1977.tb05626.x

74. Youngchaiyud U, Coates AS, Whittingham S, Mackay IR. Cellular-immune response to myelin protein: absence in multiple sclerosis and presence in cerebrovascular accidents. Aust N Z J Med (1974) 4:535-8. doi:10.1111/j. 1445-5994.1974.tb03233.x

75. Wang WZ, Olsson T, Kostulas V, Hojeberg B, Ekre HP, Link H. Myelin antigen reactive $\mathrm{T}$ cells in cerebrovascular diseases. Clin Exp Immunol (1992) 88:157-62. doi:10.1111/j.1365-2249.1992.tb03056.x

76. Becker KJ, Kalil AJ, Tanzi P, Zierath DK, Savos AV, Gee JM, et al. Autoimmune responses to the brain after stroke are associated with worse outcome. Stroke (2011) 42:2763-9. doi:10.1161/STROKEAHA.111.619593

77. Zierath D, Schulze J, Kunze A, Drogomiretskiy O, Nhan D, Jaspers B, et al. The immunologic profile of adoptively transferred lymphocytes influences stroke outcome of recipients. J Neuroimmunol (2013) 263:28-34. doi:10.1016/j. jneuroim.2013.07.014

78. Zierath D, Kunze A, Fecteau L, Becker K. Promiscuity of autoimmune responses to MBP after stroke. J Neuroimmunol (2015) 285:101-5. doi:10.1016/ j.jneuroim.2015.05.024

79. Becker KJ, Kindrick DL, Lester MP, Shea C, Ye ZC. Sensitization to brain antigens after stroke is augmented by lipopolysaccharide. J Cereb Blood Flow Metab (2005) 25:1634-44. doi:10.1038/sj.jcbfm. 9600160

80. Becker KJ, Zierath D, Kunze A, Fecteau L, Lee B, Skerrett S. The contribution of antibiotics, pneumonia and the immune response to stroke outcome. J Neuroimmunol (2016) 29(5-296):68-74. doi:10.1016/j.jneuroim.2016.04.005

81. Zierath D, Thullbery M, Hadwin J, Gee JM, Savos A, Kalil A, et al. CNS immune responses following experimental stroke. Neurocrit Care (2010) 12:274-84. doi:10.1007/s12028-009-9270-4

82. Jonelis FJ, Epstein JH, Martin G. Letter: the safety of psoralens. Arch Dermatol (1976) 112:1036. doi:10.1001/archderm.1976.01630310082033

83. Becker K, Kindrick D, McCarron R, Hallenbeck J, Winn R. Adoptive transfer of myelin basic protein-tolerized splenocytes to naive animals reduces infarct size: a role for lymphocytes in ischemic brain injury? Stroke (2003) 34:1809-15. doi:10.1161/01.STR.0000078308.77727.EA

84. Gee JM, Kalil A, Thullbery M, Becker KJ. Induction of immunologic tolerance to myelin basic protein prevents central nervous system autoimmunity and improves outcome after stroke. Stroke (2008) 39:1575-82. doi:10.1161/ STROKEAHA.107.501486

85. Gee JM, Zierath D, Hadwin J, Savos A, Kalil A, Thullbery M, et al. Long term immunologic consequences of experimental stroke and mucosal tolerance. Exp Transl Stroke Med (2009) 1:3. doi:10.1186/2040-7378-1-3

86. Frenkel D, Huang Z, Maron R, Koldzic DN, Hancock WW, Moskowitz MA, et al. Nasal vaccination with myelin oligodendrocyte glycoprotein reduces stroke size by inducing IL-10-producing CD4+ T cells. J Immunol (2003) 171:6549-55. doi:10.4049/jimmunol.171.12.6549

87. Ren X, Akiyoshi K, Grafe MR, Vandenbark AA, Hurn PD, Herson PS, et al. Myelin specific cells infiltrate MCAO lesions and exacerbate stroke severity. Metab Brain Dis (2012) 27:7-15. doi:10.1007/s11011-011-9267-5

88. Klehmet J, Hoffmann S, Walter G, Meisel C, Meisel A. Stroke induces specific alteration of $\mathrm{T}$ memory compartment controlling auto-reactive CNS antigen-specific T cell responses. J Neurol Sci (2016) 368:77-83. doi:10.1016/j. jns.2016.06.039

89. Romer C, Engel O, Winek K, Hochmeister S, Zhang T, Royl G, et al. Blocking stroke-induced immunodeficiency increases CNS antigen-specific autoreactivity but does not worsen functional outcome after experimental stroke. J Neurosci (2015) 35:7777-94. doi:10.1523/JNEUROSCI.1532-14.2015

90. Rostrom B, Link B. Oligoclonal immunoglobulins in cerebrospinal fluid in acute cerebrovascular disease. Neurology (1981) 31:590-6. doi:10.1212/ WNL.31.5.590

91. Tsementzis SA, Chao SW, Hitchcock ER, Gill JS, Beevers DG. Oligoclonal immunoglobulin G in acute subarachnoid hemorrhage and stroke. Neurology (1986) 36:395-7. doi:10.1212/WNL.36.3.395
92. Pruss H, Iggena D, Baldinger T, Prinz V, Meisel A, Endres M, et al. Evidence of intrathecal immunoglobulin synthesis in stroke: a cohort study. Arch Neurol (2012) 69:714-7. doi:10.1001/archneurol.2011.3252

93. Arasa F. (Bioengineering). Folia Clin Int (1975) 25:97-103.

94. Shibata D, Cain K, Tanzi P, Zierath D, Becker K. Myelin basic protein autoantibodies, white matter disease and stroke outcome. J Neuroimmunol (2012) 252:106-12. doi:10.1016/j.jneuroim.2012.08.006

95. Kalev-Zylinska ML, Symes W, Little KC, Sun P, Wen D, Qiao L, et al. Stroke patients develop antibodies that react with components of N-methylD-aspartate receptor subunit 1 in proportion to lesion size. Stroke (2013) 44:2212-9. doi:10.1161/STROKEAHA.113.001235

96. Zerche M, Weissenborn K, Ott C, Dere E, Asif AR, Worthmann H, et al. Preexisting serum autoantibodies against the NMDAR subunit NR1 modulate evolution of lesion size in acute ischemic stroke. Stroke (2015) 46:1180-6. doi:10.1161/STROKEAHA.114.008323

97. Yan Y, Li Y, Fu Y, Yang L, Su L, Shi K, et al. Autoantibody to MOG suggests two distinct clinical subtypes of NMOSD. Sci China Life Sci (2016) 59:1270-81. doi:10.1007/s11427-015-4997-y

98. Becker KJ, Tanzi P, Zierath D, Buckwalter MS. Antibodies to myelin basic protein are associated with cognitive decline after stroke. J Neuroimmunol (2016) 29(5-296):9-11. doi:10.1016/j.jneuroim.2016.04.001

99. Doyle KP, Quach LN, Sole M, Axtell RC, Nguyen TV, Soler-Llavina GJ, et al. B-lymphocyte-mediated delayed cognitive impairment following stroke. J Neurosci (2015) 35:2133-45. doi:10.1523/JNEUROSCI.4098-14.2015

100. Shi K, Wang Z, Liu Y, Gong Y, Fu Y, Li S, et al. CFHR1-modified neural stem cells ameliorated brain injury in a mouse model of neuromyelitis optica spectrum disorders. J Immunol (2016) 197:3471-80. doi:10.4049/ jimmunol.1600135

101. Weaver CT, Harrington LE, Mangan PR, Gavrieli M, Murphy KM. Th17: an effector CD4 T cell lineage with regulatory T cell ties. Immunity (2006) 24:677-88. doi:10.1016/j.immuni.2006.06.002

102. Zhou L, Chong MM, Littman DR. Plasticity of CD4+ T cell lineage differentiation. Immunity (2009) 30:646-55. doi:10.1016/j.immuni.2009.05.001

103. Zhang CJ, Gong Y, Zhu W, Qi Y, Yang CS, Fu Y, et al. Augmentation of circulating follicular helper $\mathrm{T}$ cells and their impact on autoreactive B cells in myasthenia gravis. J Immunol (2016) 197:2610-7. doi:10.4049/jimmunol. 1500725

104. Wang Z, Guo W, Liu Y, Gong Y, Ding X, Shi K, et al. Low expression of complement inhibitory protein CD59 contributes to humoral autoimmunity against astrocytes. Brain Behav Immun (2017) 65:173-82. doi:10.1016/j. bbi.2017.04.023

105. Ding X, Yan Y, Li X, Li K, Ciric B, Yang J, et al. Silencing IFN-gamma binding/ signaling in astrocytes versus microglia leads to opposite effects on central nervous system autoimmunity. J Immunol (2015) 194:4251-64. doi:10.4049/ jimmunol.1303321

106. Liesz A, Sun L, Zhou W, Schwarting S, Mracsko E, Zorn M, et al. FTY720 reduces post-ischemic brain lymphocyte influx but does not improve outcome in permanent murine cerebral ischemia. PLoS One (2011) 6:e21312. doi:10.1371/journal.pone.0021312

107. Wei Y, Yemisci M, Kim HH, Yung LM, Shin HK, Hwang SK, et al. Fingolimod provides long-term protection in rodent models of cerebral ischemia. Ann Neurol (2011) 69:119-29. doi:10.1002/ana.22186

108. Kraft P, Gob E, Schuhmann MK, Gobel K, Deppermann C, Thielmann I, et al. FTY720 ameliorates acute ischemic stroke in mice by reducing thromboinflammation but not by direct neuroprotection. Stroke (2013) 44:3202-10. doi:10.1161/STROKEAHA.113.002880

109. Hunter SF, Bowen JD, Reder AT. The direct effects of fingolimod in the central nervous system: implications for relapsing multiple sclerosis. CNS Drugs (2016) 30:135-47. doi:10.1007/s40263-015-0297-0

110. Cipriani R, Chara JC, Rodriguez-Antiguedad A, Matute C. Effects of FTY720 on brain neurogenic niches in vitro and after kainic acid-induced injury. J Neuroinflammation (2017) 14:147. doi:10.1186/s12974-017-0922-6

111. Dusaban SS, Chun J, Rosen H, Purcell NH, Brown JH. Sphingosine 1-phosphate receptor 3 and RhoA signaling mediate inflammatory gene expression in astrocytes. J Neuroinflammation (2017) 14:111. doi:10.1186/ s12974-017-0882-x

112. Brait VH, Tarrason G, Gavalda A, Godessart N, Planas AM. Selective sphingosine 1-phosphate receptor 1 agonist is protective against ischemia/reperfusion in mice. Stroke (2016) 47:3053-6. doi:10.1161/STROKEAHA.116.015371 
113. Sun N, Shen Y, Han W, Shi K, Wood K, Fu Y, et al. Selective sphingosine-1phosphate receptor 1 modulation attenuates experimental intracerebral hemorrhage. Stroke (2016) 47:1899-906. doi:10.1161/STROKEAHA.115.012236

114. Havrdova E, Hutchinson M, Kurukulasuriya NC, Raghupathi K, Sweetser MT, Dawson KT, et al. Oral BG-12 (dimethyl fumarate) for relapsing-remitting multiple sclerosis: a review of DEFINE and CONFIRM. Evaluation of: Gold R, Kappos L, Arnold D, et al. Placebo-controlled phase 3 study of oral BG-12 for relapsing multiple sclerosis. N Engl J Med 2012;367:1098-107; and Fox RJ, Miller DH, Phillips JT, et al. Placebo-controlled phase 3 study of oral BG-12 or glatiramer in multiple sclerosis. N Engl J Med 2012;367:1087-97. Expert Opin Pharmacother (2013) 14:2145-56. doi:10.1517/14656566.2013.826190

115. Fox RJ, Miller DH, Phillips JT, Hutchinson M, Havrdova E, Kita M, et al. Placebo-controlled phase 3 study of oral BG-12 or glatiramer in multiple sclerosis. N Engl J Med (2012) 367:1087-97. doi:10.1056/NEJMoa1206328

116. Linker RA, Lee DH, Ryan S, van Dam AM, Conrad R, Bista P, et al. Fumaric acid esters exert neuroprotective effects in neuroinflammation via activation of the Nrf2 antioxidant pathway. Brain (2011) 134:678-92. doi:10.1093/ brain/awq386

117. Bomprezzi R. Dimethyl fumarate in the treatment of relapsing-remitting multiple sclerosis: an overview. Ther Adv Neurol Disord (2015) 8:20-30. doi:10.1177/1756285614564152

118. Zhao X, Sun G, Zhang J, Ting SM, Gonzales N, Aronowski J. Dimethyl fumarate protects brain from damage produced by intracerebral hemorrhage by mechanism involving Nrf2. Stroke (2015) 46:1923-8. doi:10.1161/ STROKEAHA.115.009398

119. Yao Y, Miao W, Liu Z, Han W, Shi K, Shen Y, et al. Dimethyl fumarate and monomethyl fumarate promote post-ischemic recovery in mice. Transl Stroke Res (2016) 7:535-47. doi:10.1007/s12975-016-0496-0

120. ClausenBH,LundbergL, Yli-KarjanmaaM,MartinNA,SvenssonM,AlfsenMZ, et al. Fumarate decreases edema volume and improves functional outcome after experimental stroke. Exp Neurol (2017) 295:144-54. doi:10.1016/j. expneurol.2017.06.011

121. Fowler JH, McQueen J, Holland PR, Manso Y, Marangoni M, Scott F, et al. Dimethyl fumarate improves white matter function following severe hypoperfusion: involvement of microglia/macrophages and inflammatory mediators. J Cereb Blood Flow Metab (2017). doi:10.1177/0271678X17713105

122. Rommer PS, Dorner T, Freivogel K, Haas J, Kieseier BC, Kumpfel T, et al. Safety and clinical outcomes of rituximab treatment in patients with multiple sclerosis and neuromyelitis optica: experience from a National Online Registry (GRAID). J Neuroimmune Pharmacol (2016) 11:1-8. doi:10.1007/ s11481-015-9646-5

123. He D, Guo R, Zhang F, Zhang C, Dong S, Zhou H. Rituximab for relapsingremitting multiple sclerosis. Cochrane Database Syst Rev (2013):CD009130. doi:10.1002/14651858.CD009130.pub3

124. Zhang M, Zhang C, Bai P, Xue H, Wang G. Effectiveness of low dose of rituximab compared with azathioprine in Chinese patients with neuromyelitis optica: an over 2-year follow-up study. Acta Neurol Belg (2017) 117(3):695-702. doi:10.1007/s13760-017-0795-6

125. Annovazzi P, Capobianco M, Moiola L, Patti F, Frau J, Uccelli A, etal. Rituximab in the treatment of neuromyelitis optica: a multicentre Italian observational study. J Neurol (2016) 263:1727-35. doi:10.1007/s00415-016-8188-y

126. Kim SH, Huh SY, Lee SJ, Joung A, Kim HJ. A 5-year follow-up of rituximab treatment in patients with neuromyelitis optica spectrum disorder. JAMA Neurol (2013) 70:1110-7. doi:10.1001/jamaneurol.2013.3071
127. Yang CS, Yang L, Li T, Zhang DQ, Jin WN, Li MS, et al. Responsiveness to reduced dosage of rituximab in Chinese patients with neuromyelitis optica. Neurology (2013) 81:710-3. doi:10.1212/WNL.0b013e3182alaac7

128. Yong VW, Wells J, Giuliani F, Casha S, Power C, Metz LM. The promise of minocycline in neurology. Lancet Neurol (2004) 3:744-51. doi:10.1016/ S1474-4422(04)00937-8

129. Chen X, Ma X, Jiang Y, Pi R, Liu Y, Ma L. The prospects of minocycline in multiple sclerosis. J Neuroimmunol (2011) 235:1-8. doi:10.1016/j.jneuroim. 2011.04.006

130. Brundula V, Rewcastle NB, Metz LM, Bernard CC, Yong VW. Targeting leukocyte MMPs and transmigration: minocycline as a potential therapy for multiple sclerosis. Brain (2002) 125:1297-308. doi:10.1093/brain/ awf133

131. Metz LM, Li DKB, Traboulsee AL, Duquette P, Eliasziw M, Cerchiaro G, et al. Minocycline in, trial of minocycline in a clinically isolated syndrome of multiple sclerosis. N Engl J Med (2017) 376:2122-33. doi:10.1056/ NEJMoa1608889

132. Lampl Y, Boaz M, Gilad R, Lorberboym M, Dabby R, Rapoport A, et al. Minocycline treatment in acute stroke: an open-label, evaluator-blinded study. Neurology (2007) 69:1404-10. doi:10.1212/01.wnl.0000277487.04281.db

133. Fagan SC, Waller JL, Nichols FT, Edwards DJ, Pettigrew LC, Clark WM, et al. Minocycline to improve neurologic outcome in stroke (MINOS): a dosefinding study. Stroke (2010) 41:2283-7. doi:10.1161/STROKEAHA.110. 582601

134. Cai ZY, Yan Y, Sun SQ, Zhang J, Huang LG, Yan N, et al. Minocycline attenuates cognitive impairment and restrains oxidative stress in the hippocampus of rats with chronic cerebral hypoperfusion. Neurosci Bull (2008) 24:305-13. doi:10.1007/s12264-008-0324-y

135. Cho KO, La HO, Cho YJ, Sung KW, Kim SY. Minocycline attenuates white matter damage in a rat model of chronic cerebral hypoperfusion. J Neurosci Res (2006) 83:285-91. doi:10.1002/jnr.20727

136. Ma J, Zhang J, Hou WW, Wu XH, Liao RJ, Chen Y, et al. Early treatment of minocycline alleviates white matter and cognitive impairments after chronic cerebral hypoperfusion. Sci Rep (2015) 5:12079. doi:10.1038/ srep 12079

137. Fan R, Xu F, Previti ML, Davis J, Grande AM, Robinson JK, et al. Minocycline reduces microglial activation and improves behavioral deficits in a transgenic model of cerebral microvascular amyloid. J Neurosci (2007) 27:3057-63. doi:10.1523/JNEUROSCI.4371-06.2007

138. Manso Y, Holland PR, Kitamura A, Szymkowiak S, Duncombe J, Hennessy E, et al. Minocycline reduces microgliosis and improves subcortical white matter function in a model of cerebral vascular disease. Glia (2017) 66(1):34-46. doi:10.1002/glia.23190

Conflict of Interest Statement: The authors declare that the research was conducted in the absence of any commercial or financial relationships that could be construed as a potential conflict of interest.

Copyright (C) $2018 \mathrm{Fu}$ and Yan. This is an open-access article distributed under the terms of the Creative Commons Attribution License (CC BY). The use, distribution or reproduction in other forums is permitted, provided the original author(s) or licensor are credited and that the original publication in this journal is cited, in accordance with accepted academic practice. No use, distribution or reproduction is permitted which does not comply with these terms. 